\title{
An Ethno-botanical Overview of Oak: A Multipurpose Wild Tree Species of the Pir Panjal Himalayas
}

\author{
Mohd. Junaid Jazib, Saleem Ayaz Rather \\ Assistant Professor (Environmental Sciences), Govt. Degree College Thannamandi (Rajouri), \\ $\mathrm{J} \& \mathrm{~K}$, India \\ junaidjazib@gmail.com
}

\begin{abstract}
Oak is a very important tree species in the temperate broadleaved Himalayan forests. It is valued for a multitude of benefits reaped by the locals in the PirPanjal Himalayas. In the traditional agro-pastoral setup, their socioeconomy rely greatly on the tree species. Quercus leucotrichophora and Q. floribunda are the two dominant species growing wild in the region. An attempt is made in the present study to investigate and expose the type and extent of the role played by this tree in the livelihoods of rural populations. Certain factors responsible for regular shrinkage of oak forests in the area have also been assessed briefly.
\end{abstract}

Keywords: Agroforestry, wild-tree-species, ecosystem, ethnobotanical-uses.

\section{Introduction}

Forests constitute a very important resource base in the Himalayas, the world's youngest mountain range, which covers over one fifths (18\%) of India's geographical area. The temperate broadleaved forests form the most significant ecosystems in the foothills and the mountainous regions of the mighty Himalayas throughout. These forests despite being very rich in their floral composition are, by and large dominated by a few widely distributed plant genera, essentially and importantly including the species of Quercus commonly known as oak. aabout 35 species of Quercus are distributed between 1000-3500 m elevations (Singh and Rawat) either in abundance or somewhat narrowly from the north eastern to the westernmost part of the Himalayas. The Himalaya is also the home of many unique and diverse human groups, living in the river valleys and mountain slopes which differ from each other in terms of language, culture, tradition, religion and patterns of resource use. They have been subsisting on the Himalayan natural resources for millennia (Singh and Rawat).

Pir Panjal range of mountains, comprising of rocky peaks and undulating valleys lies in the north western part of the Inner Himalayas. The rich biodiversity of the region is extensively utilized in various forms including medicine, food, fuel, fodder, fiber and timber by the inhabitants who themselves exhibit rich ethno-cultural diversity. Oak, vernacularly known as Reen or Banjj, is a medium to very large sized naturally growing tree which is, ecologically as well as economically, one of the most important tree genera in the Pir Panjal foothills with its several species and variants richly growing in the region. Oak forests, which form a considerably large part of vegetation in the Pir Panjal Himalayas, are perhaps the most exploited (mainly in non-commercial manner) woodlands here. The tree can rightly be termed as a multipurpose tree species which besides its ecosystem services provides livelihood to the locals. It has assumed sort of socio-cultural importance among the rural tribals and nomads whose socio-economy reliably revolve around the tree and who are without having much diversified subsistence. Thus the economically not so sound people of the area owe a great deal to the species which serve many purposes concurrently like providing fodder, fuel wood, timber and constructional wood, etc. Moreover, from ethnobotanical point of view, the locals possess a great deal of knowledge accumulated and preserved over centuries. Their knowledge about species providing a multitude of services for their livelihood is certain to be exhaustive and valuable. In recent decades, however, with increase in human population, tourism, over exploitation, widespread logging, overgrazing, removal of leaf and wood, etc. the oak forests are facing grave threats. The problem stands aggravated by some natural factors including low regeneration and pathogenic causes. The present study aims at exploring and documenting the traditional ways and procedures of plant use in the study area, with special reference to the multiple uses of single tree species growing in wild.

\section{Materials and Methodology}

\subsection{Study Area}

Pir Panjal is part of the North Western Himalayas. It runs in southeast to northwest direction from Jammu Shivaliks to Banihal in the Indian state of Jammu and Kashmir. Rajouri and Poonch, the twin hilly districts lying on the southern aspect of the range form the politico-administrative mapping of the Pir Panjal Himalayas which consists of hills and slopes generally harboring a good deal of floral and faunal biodiversity. The area exhibits 
wide variation in the altitude, rain fall, temperature and soil conditions. Average elevations above mean sea level varies from $1700 \mathrm{~m}$ to $4100 \mathrm{~m}$. Summers are wet and mild whereas winters are harsher. Upper parts of the foothills witness heavy rains or moderate snowfall whereas mountainous peaks receive heavy snowfall during winters. In the Moonsoon season the area obtains a good deal of precipitation. The region is home to large chunks tribals viz. Gujjars ( Poonch:40.12\%; Rajouri:33.19\%). Area bears good forests of coniferous species (pines, cedar, birches, etc.) in higher reaches and broadleaved species(oaks, etc.) on lower slopes.

\subsection{Data Collection and Analysis}

Virtual touring of the study area was undertaken to ascertain information on relevant aspects of people-forest relationship. Eight villages, each in the neighborhood of an oak-forest, were selected for the study after extensive surveying in the area. An ethnobotanical approach was adopted for the study.

After collecting primary data on distribution and extent of oak forests or trees in and around the croplands, the emphasis was laid on identifying and enumerating the types of tangible services oak trees offer to the local inhabitant. In addition to real-time observations, data (on various uses of the tree) was recorded through former interviews and casual discussions with farmers, shepherds, households, housewives, elderly people etc. Special care, however, was taken to verify the information received from the respondents. The data collected was analyzed and arranged in logical and presentable form.

\section{Results and discussion}

Oak(Quercus spp) is found to grow on cool moist soils of temperate climates at up to $3000 \mathrm{~m}$ elevations, either in pure or in mixed forests along with conifers, rhododendrons, walnut, horse chest-nut, birches, maples, etc. The magnificent tree, rising up to $40 \mathrm{~m}$ tall with a trunk up to $1.5 \mathrm{~m}$ or more in diameter, has beautiful dark green to grayish leaves(ovate-elliptic in shape) with whitish underneath and sharp to thorny or lobed leaf margins in some species. The lurching bunches of beautiful long catkins, as the flowers are known in its case, present arresting view on the onset of the spring when the gregariously growing trees blossom and often induce the nomadic Gujjar boys and girls to singing and rejoicing clamorously. Fruit a nut called an acorn, is borne in a cup-like structure known as capsule; each acorn containing one seed, is collected, roasted in open hearths and eaten by the children of the forest dwellers. The crowded woods of splendid oak trees spreading over vast undulating hillocks present stunning view in the serene backdrop of snow clad mountainous tops. Though growing wildly and nowhere domesticated the large and sky-high tall trees in and around agricultural fields, standing elegantly like sentries, give a graceful look besides serving number of other principal economic and ecological purposes. Large sized trees in mixed deciduous forests often become of typical scenic value by their above canopy emergence. There are two species of oak or Reen and Banjj namely Quercus leucotrichophora (reeN) and Q. floribunda (mhooru) which predominantly grow in the Rajouri Poonch region. The tree is intricately associated not only with agro-pastoral ecosystems of the rural populace here but, in a broader sense, with the life support system in the region where the modern facilities of life are still a far off matter. It has assumed sort of sociocultural importance among the rural tribals and nomads whose socio-economy reliably revolve around the tree and who are without having much diversified subsistence. Their heavy and multifarious dependence upon the species is due to the fact that a large chunk of the populace (being rural or agrarian in character) is associated with pastoralism and farming. Thus the economically not so sound people of the area owe a great deal to the species which serve many purposes concurrently like providing fodder, fuel wood, timber and constructional wood, etc. The palatable and nutritious Leaves of the tree (ReeN and Banjj) are an excellent fodder for livestock especially for cows and buffaloes and many a households who have very little of land to grow other fodder crops almost solely depend upon it. Foliage is also customarily used for spreading material and roofing in mud houses in hilly habitations. In agricultural implements yoke, ploughs, tool handles, etc. are exclusively made from the oak wood. Tree is expansively used as fuel wood in hilly areas. Charcoal obtained by oxygen deficient heating of the branches and twigs of oak is not only stored for winter usages in households but is of preferred by local iron workers. It is also at times sold in the nearby markets and urban settings during winters when the electric power supply habitually play hide and seek. Owing to its high density (of about $0.75 \mathrm{~g} / \mathrm{cm}^{3}$ ) Oak wood has great strength and hardness and is used for building residential houses, cowsheds and especially for erecting temporary huts in upper reaches for seasonal or transhumant uses by the nomads during their rotational stays. The pillars, the beams, the roof-supports and the roofing material all are preferably made from the oak wood. For it having good nail holding capacity and acceptable smoothness wood is commonly used for doors, window and paneling. Wood is very resistant to insect and fungal attack because of its high tannin content its planks and sawn blocks are used for many other household and constructional purposes.

Fruit or acorn of oak is supposed to possess medicinal properties and is often administered to livestock as well as humans for certain gastric and other ailments. Even bark of the young branches is helpful in treating some ungulates' diseases as reportedly practiced by nomadic Gujjars in Kotranka area of Rajouri. Recreational purpose is also served when locals and shepherds enthusiastically climb the mighty trees and casually organize such competitions to display their strength and vigor. 
The branches of oak are used as fencing material in the rural Rajouri Poonch to demarcate and protect territorial boundaries in the hills. Ecologically oak provides a wide range of ecosystem services including soil formation and its protection from erosion, replenishing crop land fertility, maintaining the health of mountain streams and regulating the hydrological regime, helping to stabilize local and regional climate through direct influences, building up a moisture regime favorable to wild species as well as those of agronomic and horticultural value and creating surplus for possible carbon trading at international level.

Regrettably the vast landscape in the Pir Panjal region has been deprived of hitherto abundantly growing oak forests particularly during the last decades of turmoil and disturbance in the state. Large areas had been clear felled by the local contractors and forest smugglers. Even the Police department and central police and security agencies have remained largely involved in ruthless removal of the tree cover merely for fuel wood purposes. For several years now some disease has attacked the tree species which is an added threat to its existence otherwise believed to be a ubiquitous in Pir Panjal range. A large scale action plan and an effective campaign is required to be in place to save the species for its local socio-economic vitality as well as in larger interest of the humanity for its greater ecological significance.

\section{Conclusion}

Oak is a very important tree species growing wild in the Pir Panjal Himalayan region in Indian state of Jammu and Kashmir. Though nowhere grown artificially in the region, the tree is put to a wide range of uses by the local populations. The economy and livelihood of the locals revolve dependably around the tree species. In the recent years, however, oak plantations in the region have declined to alarming limits. This is a concern not for the locals point of view only but also from biodiversity point of view.

\section{Acknowledgement}

Special thanks are due to the locals in the study area for sharing their ideas and perceptions and for their hospitability. The author is indebted to Dr. B.B Sharma, the Principal, Government Degree College Thannamandi (Rajouri) without whose patronage this work would have not been possible.

\section{References}

- $\quad$ Bisht, H, Vinay Prakash and A R Natyal, Factors Affecting Regeneration Potential of Q semecarpifolis: A Poorly Regenerated Oak of Himalayan Timberline, Research Journal of Seed Science 5(2):63-70,2012.

- Jazib, Mohd Junaid, Forest Dependence and the Utilization Patterns of the Local in the PirPanjal Himalayas, Civil and Environmental Research, Vol.7, No.1, 2015.

- Jazib, M Junaid, The Spectacular oak, Daily Excelsior dtd. 12/05/2013, Jammu, India

- Singh, Gajendra and G. S. Rawat, Depletion of Oak (Quercus spp.) Forests in the Western Himalaya: Grazing, Fuelwood and Fodder Collection, Global Perspectives on Sustainable Forest Management. 2012.

- Singh, S.P. (1981), Rural Ecosystem and Development in the Himalaya. In J.S. Singh, S.P. Prakashan, Nainital, India.

- $\quad$ Troup, R.S. (1921), Silviculture of Indian Trees. Vol. I-III. Clarendon Press, Oxford. 


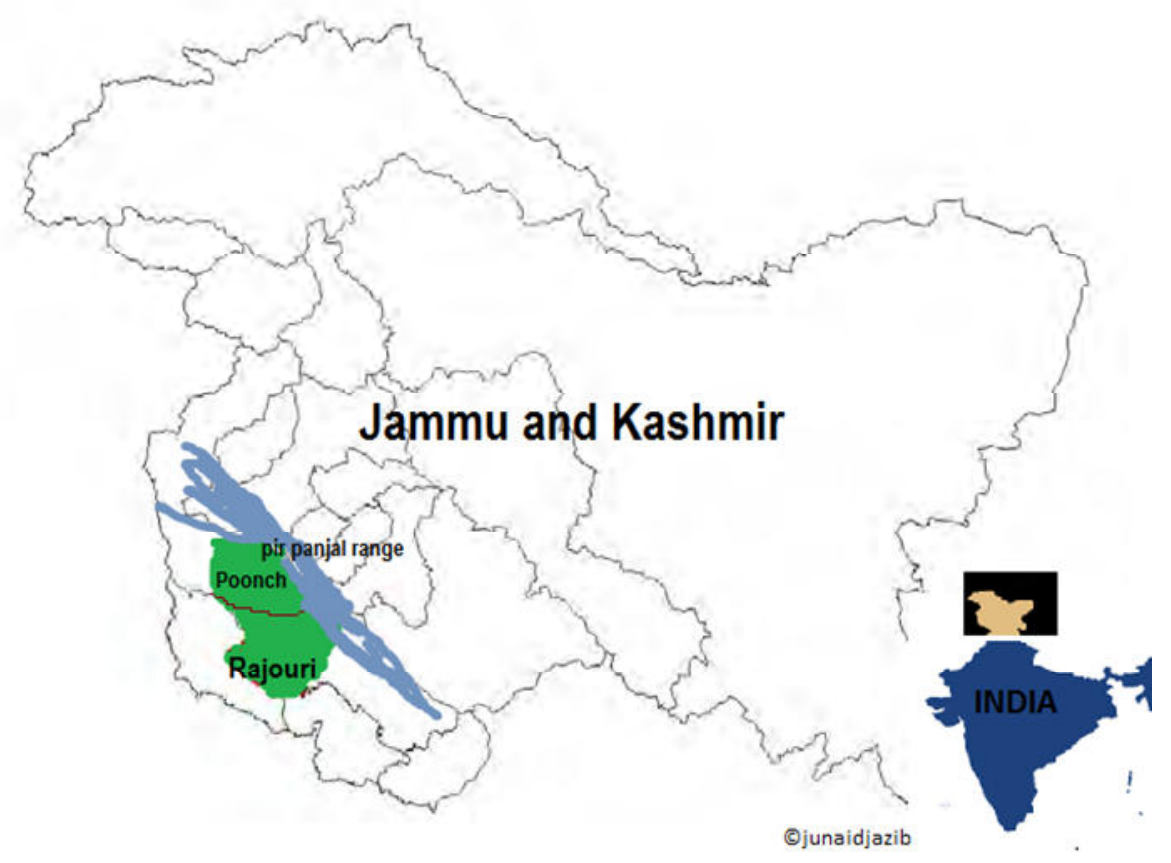

Figure 1 Study area(Rajouri \& Poonch districts)

Table 1 Socio-cultural setting of the study area

\begin{tabular}{|l|l|l|}
\hline Average Family Size & \multicolumn{2}{|l|}{06 members } \\
\hline Family Type & Joint as well Nuclear \\
\hline Economic Class & Above Poverty Line & $35 \%$ \\
\cline { 2 - 3 } & Below Poverty Line & $65 \%$ \\
\hline Economic Avtivity & Agricutural & $59 \%$ \\
\cline { 2 - 3 } & Nomadism & $35 \%$ \\
\cline { 2 - 3 } & Labour & $02 \%$ \\
\cline { 2 - 3 } & Others(Govt /prvt job) & $04 \%$ \\
\hline
\end{tabular}




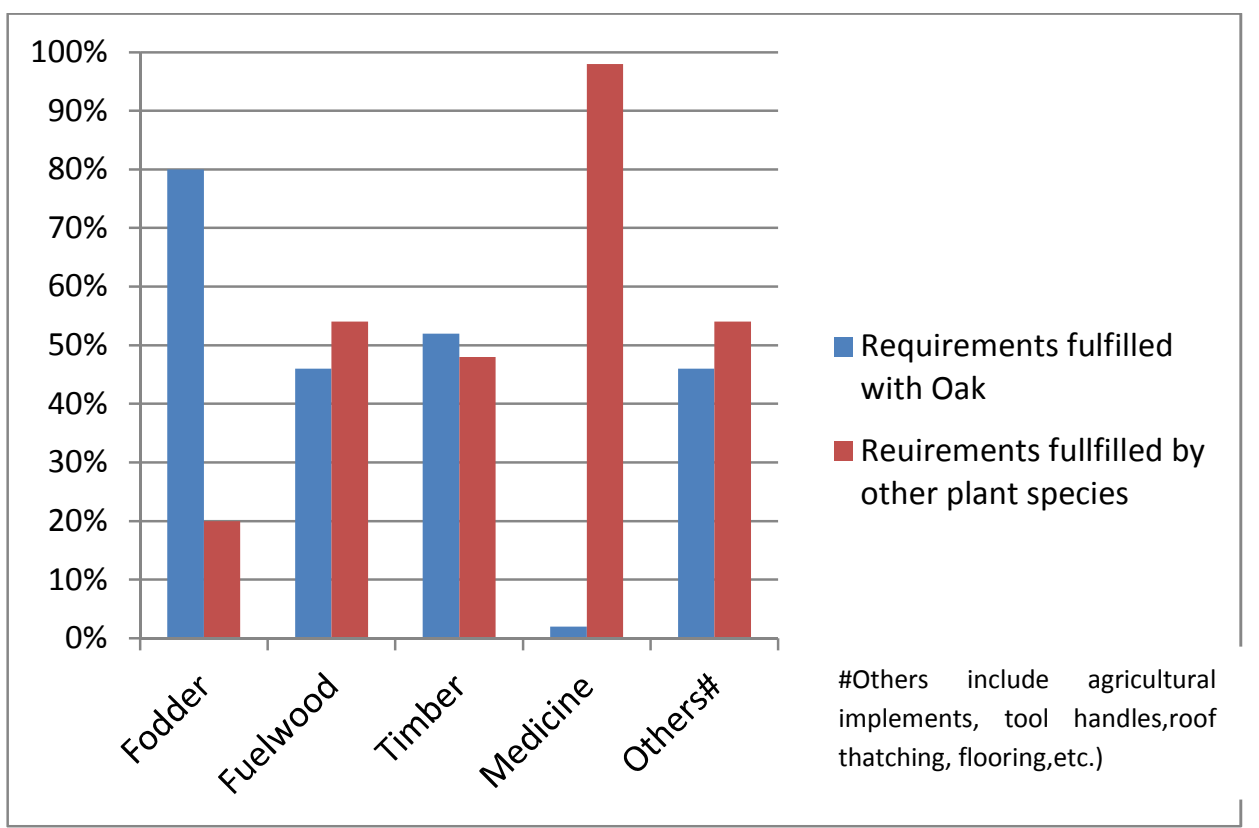

Figure 2 Extent of rural inhabitants' basic requirements met with oak visa-vis rest of the plant species

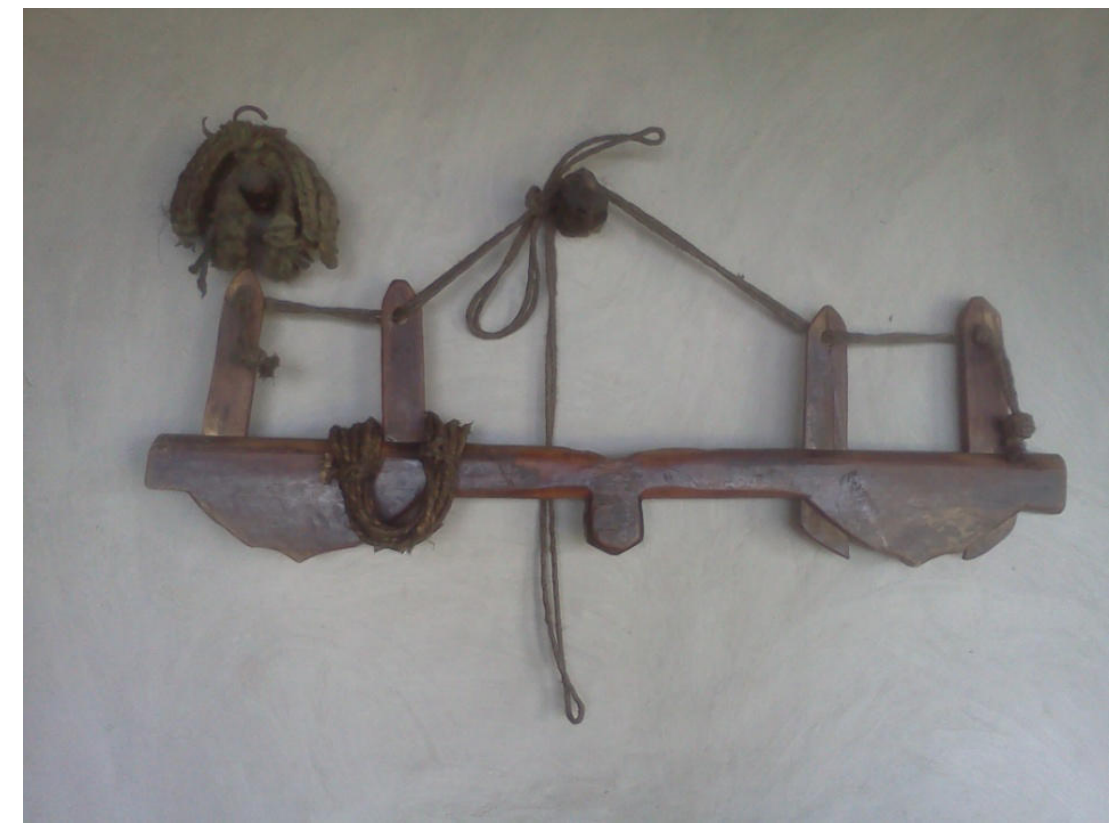

Figure 3 A yoke (a farm tool used with plough) made of Quercus

\section{leucotrichophora}




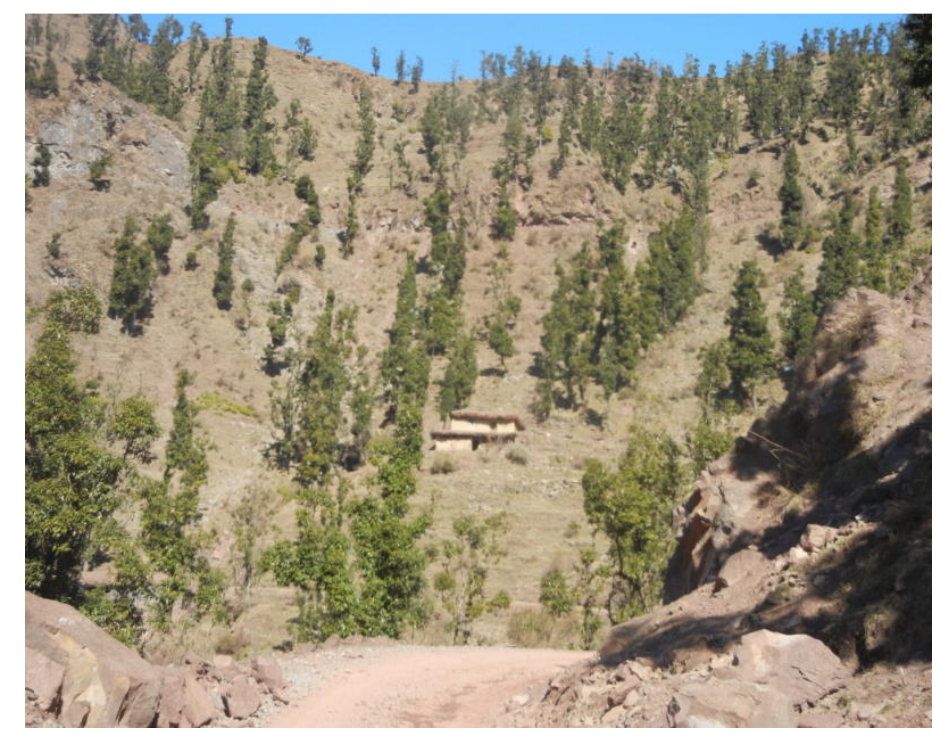

Figure 4 A degraded oak forest in the study area(village Badhal (Kotranka) 
The IISTE is a pioneer in the Open-Access hosting service and academic event management. The aim of the firm is Accelerating Global Knowledge Sharing.

More information about the firm can be found on the homepage:

http://www.iiste.org

\section{CALL FOR JOURNAL PAPERS}

There are more than 30 peer-reviewed academic journals hosted under the hosting platform.

Prospective authors of journals can find the submission instruction on the following page: http://www.iiste.org/journals/ All the journals articles are available online to the readers all over the world without financial, legal, or technical barriers other than those inseparable from gaining access to the internet itself. Paper version of the journals is also available upon request of readers and authors.

\section{MORE RESOURCES}

Book publication information: http://www.iiste.org/book/

Academic conference: http://www.iiste.org/conference/upcoming-conferences-call-for-paper/

\section{IISTE Knowledge Sharing Partners}

EBSCO, Index Copernicus, Ulrich's Periodicals Directory, JournalTOCS, PKP Open Archives Harvester, Bielefeld Academic Search Engine, Elektronische Zeitschriftenbibliothek EZB, Open J-Gate, OCLC WorldCat, Universe Digtial Library, NewJour, Google Scholar

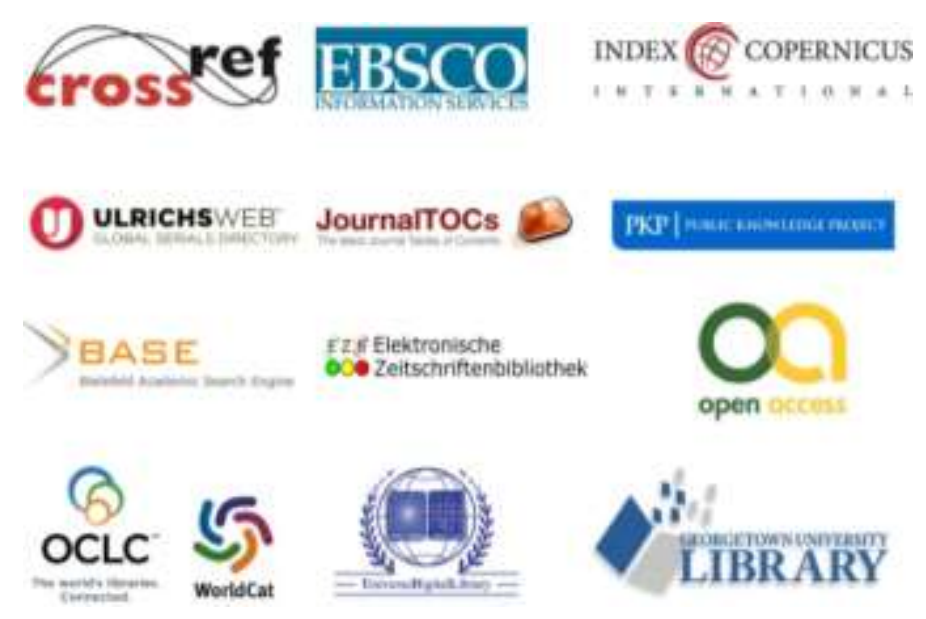

